\title{
MODIFICATION BY ASCORBIC ACID AND BRITISH ANTI- LEWISITE OF THE EFFECT OF MERCUHYDRIN ON RENAL TUBULAR FUNCTION IN MAN ${ }^{1}$
}

\author{
By HALL S. TACKET AND MORTON L. GUBIN \\ (From the Department of Medicine, University of Tennessee College of Medicine, and the \\ John Gaston Hospital, Memphis, Tenn.)
}

(Submitted for publication December 23, 1952; accepted February 18, 1954)

Alteration of renal hemodynamics and tubular function following administration of organic mercurial compounds has been investigated by several workers $(1,2)$. These compounds have no effect on the glomerular filtration rate or effective renal plasma flow. The maximal capacity of the tubules to excrete para-aminohippurate in man $\left(\mathrm{Tm}_{\mathrm{PAB}}\right)$ is depressed by the administration of mercurial diuretics. Berliner, Kennedy, and Hilton (1) observed depression of $\mathrm{Tm}_{\mathrm{PAB}}$ varying from 67 to 83 per cent of the control values after administration of Salyrgan ${ }^{2}$ to five human subjects. Our unpublished observations confirm that administration of Mercuhydrin ${ }^{3}$ also depresses $\mathrm{Tm}_{\mathrm{PAB}}$ to a similar degree. Berliner, Kennedy, and Hilton also found that the depressed tubular excretion of PAH following administration of Salyrgan may be restored to the control value by injection of British Anti-Lewisite (BAL, 2, 3-dimercapto propanol). Ruskin, Ruskin, and Nowinski (3) report that ascorbic acid protects against the respiratory depression of rat kidney slices observed following exposure to Mercuhydrin. This observation suggested to us that ascorbic acid might also prevent the depression of $\mathrm{Tm}_{\mathrm{PAB}}$ induced by Mercuhydrin. Our experiments demonstrate that ascorbic acid is virtually as effective as BAL in inhibiting the depression of $\mathrm{Tm}_{\mathrm{PAB}}$ that follows administration of Mercuhydrin.

\section{METHODS}

Patients were selected on the wards at random. Those having far advanced renal disease and congestive heart

1 Supported in part by a Cardiovascular Training Grant from the National Heart Institute, U. S. Public Health Service.

2 Salyrgan (sodium salt of 0-(3-hydroxymercuri-2methoxypropyl) carbamyl phenoxyacetic acid) is manufactured by Winthrop-Stearns, Inc., Rensselaer, New York.

${ }^{8}$ Mercuhydrin (sodium salt of methoxy-oxymercuripropyl succinyl urea with aminophyllin) is manufactured by the Lakeside Laboratories, Milwaukee, Wis. failure were excluded. After fasting overnight the subject was given 1,500 cc. of tap water 30 minutes before each procedure to induce adequate urinary flow. Priming doses of $50 \mathrm{cc}$. of 25 per cent mannitol and $50 \mathrm{cc}$. of 20 per cent sodium para-aminohippurate (PAH) were injected intravenously. Continuous intravenous infusions of mannitol and PAH were maintained throughout the course of each experiment so that plasma levels of these substances remained fairly constant. After an equilibration period of 20 minutes, clearances were measured in two successive periods of 15 minutes each and averaged. Urine specimens were collected through an indwelling catheter, and the bladder was irrigated with 20 cc. saline and flushed with air at the beginning and end of each period. Venous blood samples were drawn at the beginning and end of each period. Plasma levels of PAH were maintained above $30 \mathrm{mg}$. per $100 \mathrm{cc}$. in all determinations of $\mathrm{Tm}$. Blood and urinary specimens were analyzed for mannitol and PAH by methods described in the literature (4). Clearance of mannitol was regarded as a close approximation of the glomerular filtration rate.

In six subjects, after the control clearance was determined, $150 \mathrm{mg}$. of ascorbic acid was given intravenously. Then two measurements of mannitol clearance and $T_{m_{P A B}}$ in successive 15 -minute periods were made and averaged. Next, Mercuhydrin, $2.0 \mathrm{cc}$., was injected and the mannitol clearance and $\mathrm{Tm}_{\mathrm{PAB}}$ again measured in two periods beginning 30 minutes after the injection. In five other subjects, BAL, $3.0 \mathrm{mg}$. per kilogram of body weight, was injected intramuscularly at the same time that Mercuhydrin was injected intravenously. Mannitol clearance and $T_{m_{P A B}}$ were determined in two successive periods beginning 30 minutes later.

\section{RESULTS}

Ascorbic acid alone had no significant influence on $\operatorname{Tm}_{\mathbf{P A B}}$ (Table I). The average $\mathrm{Tm}_{\mathrm{PAB}}$ in six subjects prior to injection of ascorbic acid was $58.8 \mathrm{mg}$. per minute compared to $60.8 \mathrm{mg}$. following ascorbic acid. Ascorbic acid protects against the depression of $\mathrm{Tm}_{\mathbf{P A B}}$ induced by Mercuhydrin. The average $\mathrm{Tm}$ following ascorbic acid and Mercuhydrin was 57.1 per 100 cc., or 94 per cent of the control value. No correlation is apparent between the degree of depression of $\mathrm{Tm}_{\mathrm{PAH}}$ and the diuretic response. 
TABLE I

Glomerular filtration rate, $T m_{P A B}$, and urine flow following intravenous ascorbic acid and Mercuhydrin

\begin{tabular}{|c|c|c|c|c|c|c|c|c|c|c|c|c|}
\hline \multirow[b]{2}{*}{ Patient } & \multicolumn{4}{|c|}{$\begin{array}{l}\text { Glomerular filtration rate } \\
c c . / m i n .\end{array}$} & \multicolumn{4}{|c|}{$\underset{\text { mg. } / \min }{\operatorname{Tmpar}}$} & \multicolumn{4}{|c|}{$\begin{array}{l}\text { Urine flow } \\
\text { cc./min. }\end{array}$} \\
\hline & Control & $\begin{array}{l}\text { After } \\
\text { As.A.* }\end{array}$ & $\begin{array}{l}\text { After } \\
\text { As.A. } \\
\text { and Hg }\end{array}$ & $\% \dagger$ & Control & $\begin{array}{l}\text { After } \\
\text { As.A. }\end{array}$ & $\begin{array}{c}\text { After } \\
\text { As.A. } \\
\text { and } \mathrm{Hg}\end{array}$ & $\%$ & Control & $\begin{array}{l}\text { After } \\
\text { As.A. }\end{array}$ & $\begin{array}{c}\text { After } \\
\text { As.A. } \\
\text { and } \mathbf{H g}\end{array}$ & $\%$ \\
\hline $\begin{array}{l}\text { M. K. } \\
\text { W. H. } \\
\text { F. H. } \\
\text { A. B. } \\
\text { W. S. } \\
\text { L. F. }\end{array}$ & $\begin{array}{r}71.2 \\
108.9 \\
82.5 \\
88.7 \\
75.4 \\
103.8\end{array}$ & $\begin{array}{r}73.0 \\
119.9 \\
69.4 \\
108.5 \\
63.3 \\
82.4\end{array}$ & $\begin{array}{r}98.3 \\
147.4 \\
67.5 \\
122.5 \\
78.4 \\
105.9\end{array}$ & $\begin{array}{r}135 \\
123 \\
97 \\
113 \\
123 \\
128\end{array}$ & $\begin{array}{l}56.2 \\
75.8 \\
54.5 \\
64.3 \\
47.3 \\
54.7\end{array}$ & $\begin{array}{l}59.0 \\
79.8 \\
57.4 \\
58.8 \\
42.8 \\
66.7\end{array}$ & $\begin{array}{l}48.4 \\
73.6 \\
55.1 \\
59.2 \\
42.2 \\
64.2\end{array}$ & $\begin{array}{r}82 \\
92 \\
96 \\
101 \\
100 \\
96\end{array}$ & $\begin{array}{l}4.43 \\
5.50 \\
3.90 \\
9.94 \\
4.35 \\
3.35\end{array}$ & $\begin{array}{l}4.60 \\
4.90 \\
4.20 \\
9.10 \\
4.83 \\
4.48\end{array}$ & $\begin{array}{r}5.60 \\
7.10 \\
13.10 \\
17.88 \\
6.13 \\
8.75\end{array}$ & $\begin{array}{l}122 \\
145 \\
312 \\
196 \\
127 \\
196\end{array}$ \\
\hline Averages & 88.4 & 86.1 & 103.3 & 119 & 58.8 & 60.8 & 57.1 & 94 & 5.25 & 5.35 & 9.76 & 182 \\
\hline
\end{tabular}

*As.A. = Ascorbic Acid.

$\dagger$ Per cent $=\frac{\text { As.A. }+\mathrm{Hg}}{\text { After As.A. }} \times 100$.

$\ddagger$ Values uncorrected for surface area.

The results when BAL was given with the Mercuhydrin were similar to those when ascorbic acid was given (Table II). The average control $T \mathrm{~m}_{\mathrm{PAB}}$ in five patients was $57.1 \mathrm{mg}$. per minute; following coincident administration of $\mathrm{BAL}$ and Mercuhydrin it was $57.2 \mathrm{mg}$. per minute, almost precisely 100 per cent of the control.

Although both BAL and ascorbic acid protected against a decrease in $\mathrm{Tm}_{\mathbf{P A B}}$ following administration of Mercuhydrin, moderate diuretic responses occurred. This may have been due to the xanthine contained in Mercuhydrin and to the osmotic effect of the continuous infusion of mannitol. No conclusions are justified regarding inhibition of diuresis by coincident administration of $\mathrm{BAL}$ or ascorbic acid with Mercuhydrin.

\section{COMMENT}

The capacity of mercurial diuretics to depress the transport of $\mathrm{PAH}$ across the renal tubular membrane in man is in contrast to the effect of this agent in the dog, but corresponds to the effect in the rat (5). The protection of $T \mathrm{~m}_{\mathrm{PAH}}$ from mercurial effect and the inhibition of mercurial diuresis by BAL are in accord with the known properties of this agent. Benesch and Benesch (6) showed that BAL combines stoichiometrically with Mercuhydrin to produce a compound that is physiologically inactive. Handley and Lavick (7) reported that organic mercurials inactivate the succinic dehydrogenase system in the renal tubules of the rat and dog. The succinic dehydrogenase system contains sulfhydryl groups susceptible to combination with mercury. They, as well as Farah and Maresh (8), suggest that this system may be implicated in salt and water resorption, since its protection by BAL coincides with reduced diuretic effect of mercurials. Fawaz and Fawaz (9) concluded, on the contrary, that this constitutes insufficient evidence to implicate the succinic dehydrogenase system in the resorption of salt and water. They point out that its inacti-

TABLE II

Glomerular filtration rate and $T m_{P A B}$ following administration of Mercuhydrin and $B A L$

\begin{tabular}{|c|c|c|c|c|c|c|}
\hline \multirow[b]{2}{*}{ Patient } & \multicolumn{3}{|c|}{$\begin{array}{l}\text { Glomerular filtration rate } \\
c c . / \min \text {. }\end{array}$} & \multicolumn{3}{|c|}{$\underset{m g . / \min .}{\operatorname{TmpaB}}$} \\
\hline & Control & $\begin{array}{c}\text { Hg and } \\
\text { BAL }\end{array}$ & $\begin{array}{l}\text { Per cent } \\
\text { of control }\end{array}$ & Control & $\underset{\text { BAL }}{\mathrm{Hg} \text { and }}$ & $\begin{array}{l}\text { Per cent } \\
\text { of control }\end{array}$ \\
\hline $\begin{array}{l}\text { Q. G. } \\
\text { H. C. } \\
\text { F. O. } \\
\text { A. P. } \\
\text { I. B. }\end{array}$ & $\begin{array}{r}94.3 \\
91.9 \\
133.3 \\
94.3 \\
122.0\end{array}$ & $\begin{array}{r}110.8 \\
102.2 \\
117.2 \\
86.7 \\
122.3\end{array}$ & $\begin{array}{r}118 \\
111 \\
88 \\
92 \\
100\end{array}$ & $\begin{array}{l}47.4 \\
48.8 \\
87.5 \\
59.2 \\
42.8\end{array}$ & $\begin{array}{r}37.1 \\
46.2 \\
109.4 \\
49.3 \\
44.7\end{array}$ & $\begin{array}{r}78 \\
95 \\
125 \\
83 \\
104\end{array}$ \\
\hline Averages & 107.2 & 107.8 & 100 & 57.1 & 57.2 & 100 \\
\hline
\end{tabular}


vation by the mercurials may be only one of many effects of this agent upon the renal tubules.

The ability of ascorbic acid to prevent the decrease in $\mathrm{Tm}_{\mathbf{P A B}}$ following administration of Mercuhydrin may be predicted from clinical experience that ascorbic acid neutralizes toxic effects of arsenic and mercury. The practice of administering ascorbic acid with mercurial diuretics to provide protection against cardiac intoxication is well founded $(10,11)$. Our results indicate that ascorbic acid also blocks at least one effect of Mercuhydrin on the kidney, the ability of Mercuhydrin to depress $\mathrm{Tm}_{\mathrm{PAH}}$. In this respect it is effective to the same degree as BAL. Speculation suggests that this blocking effect of ascorbic acid may depend upon its capacity as a reducing agent (12). It may reduce soluble mercuric salts, at the cellular level, to insoluble and perhaps physiologically inactive mercurous salts.

Our data are insufficient to indicate whether prevention of the decrease in $\mathrm{Tm}_{\mathbf{P A B}}$ following injection of Mercuhydrin influences the diuretic potency of Mercuhydrin. The clinical practice of administering ascorbic acid with Mercuhydrin must be evaluated in the light of this possibility. Although Shaffer (13) reported that ascorbic acid potentiates the diuretic effect of Mercupurin, the effect was observed in subjects that had been saturated with ascorbic acid. His observation might not be applicable in the routine clinical use of the two agents.

\section{SUMMARY}

Following control determination of glomerular filtration rate and maximal tubular excretion of para-aminohippurate $\left(\operatorname{Tm}_{\mathbf{P A H}}\right)$, these functions were observed in man in two sets of circumstances: (1) Immediately following the intravenous injection of ascorbic acid, and in the same subjects successively, 30 minutes after the intravenous injection of Mercuhydrin; and (2) 30 minutes after the concomitant injections of BAL intramuscularly and Mercuhydrin intravenously. Ascorbic acid alone did not influence glomerular filtration rate or $T_{m_{P A B}}$, but protected against the depression of $\mathrm{Tm}_{\mathbf{P A B}}$ usually induced by Mercuhydrin. Concomitant administration of BAL also protected against the depression of $T \mathrm{~m}_{\mathrm{PAB}}$ induced by Mercuhydrin. The data do not establish whether diuretic potency of Mercuhydrin is altered by concomitant administration of ascorbic acid. This possibility is suggested, however, and is worthy of further investigation.

\section{REFERENCES}

1. Berliner, R. W., Kennedy, T. J., Jr., and Hilton, J. G., Salyrgan and renal tubular secretion of para-aminohippurate in the dog and man. Am. J. Physiol., 1948, 154, 537.

2. Grossman, J., Weston, R. E., Edelman, I. S., and Leiter, L., Clinical and physiological studies on Thiomerin-a subcutaneously injectable mercurial diuretic. Federation Proc., 1949, 8, 62.

3. Ruskin, A., Ruskin, B., and Nowinski, W., Protective effect of ascorbic acid against the depression of respiration of rat heart and kidney slices by Mercuhydrin. Am. J. Med., 1951, 11, 616.

4. Smith, H. W., Finkelstein, N., Aliminosa, L., Crawford, B., and Graber, M., The renal clearances of substituted hippuric acid derivatives and other aromatic acids in dog and man. J. Clin. Invest., 1945, 24, 388.

5. Dicker, S. E., The action of mersalyl, calomel and theophylline sodium acetate on the kidney of the rat. Brit. J. Pharmacol., 1946, 1, 194.

6. Benesch, R., and Benesch, R. E., Mechanism of inactivation of mercurial diuretics by BAL. Federation Proc., 1952, 11, 186.

7. Handley, C. A., and Lavick, P. S., Inhibition of the kidney succinic dehydrogenase system by mercurial diuretics. J. Pharmacol \& Exper. Therap., 1950, 100, 115.

8. Farah, A., and Maresh, G., The influence of sulfhydryl compounds on diuresis and renal and cardiac circulatory changes caused by mersalyl. J. Pharmacol. \& Exper. Therap., 1948, 92, 73.

9. Fawaz, G., and Fawaz, E. N., Mechanism of action of mercurial diuretics. Proc. Soc. Exper. Biol. \& Med., 1951, 77, 239.

10. Chapman, D. W., and Shaffer, C. F., Mercurial diuretics. A comparison of acute cardiac toxicity in animals and the effect of ascorbic acid on detoxification in their intravenous administration. Arch. Int. Med., 1947, 79, 449.

11. Ruskin, A., and Johnson, J. E., Cardiodepressive effects of mercurial diuretics. Cardioprotective value of BAL, ascorbic acid and thiamin. Proc. Soc. Exper. Biol. \& Med., 1949, 72, 577.

12. Bundesen, H. N., Aron, H. C. S., Greenebaum, R. S., Farmer, C. J., and Abt, A. F., The detoxifying action of vitamin $C$ (ascorbic acid) in arsenical therapy. J. A. M. A., 1941, 117, 1692.

13. Shaffer, C. F., The diuretic effect of ascorbic acid. Preliminary report on its use in cardiac decompensation. J. A. M. A., 1944, 124, 700. 